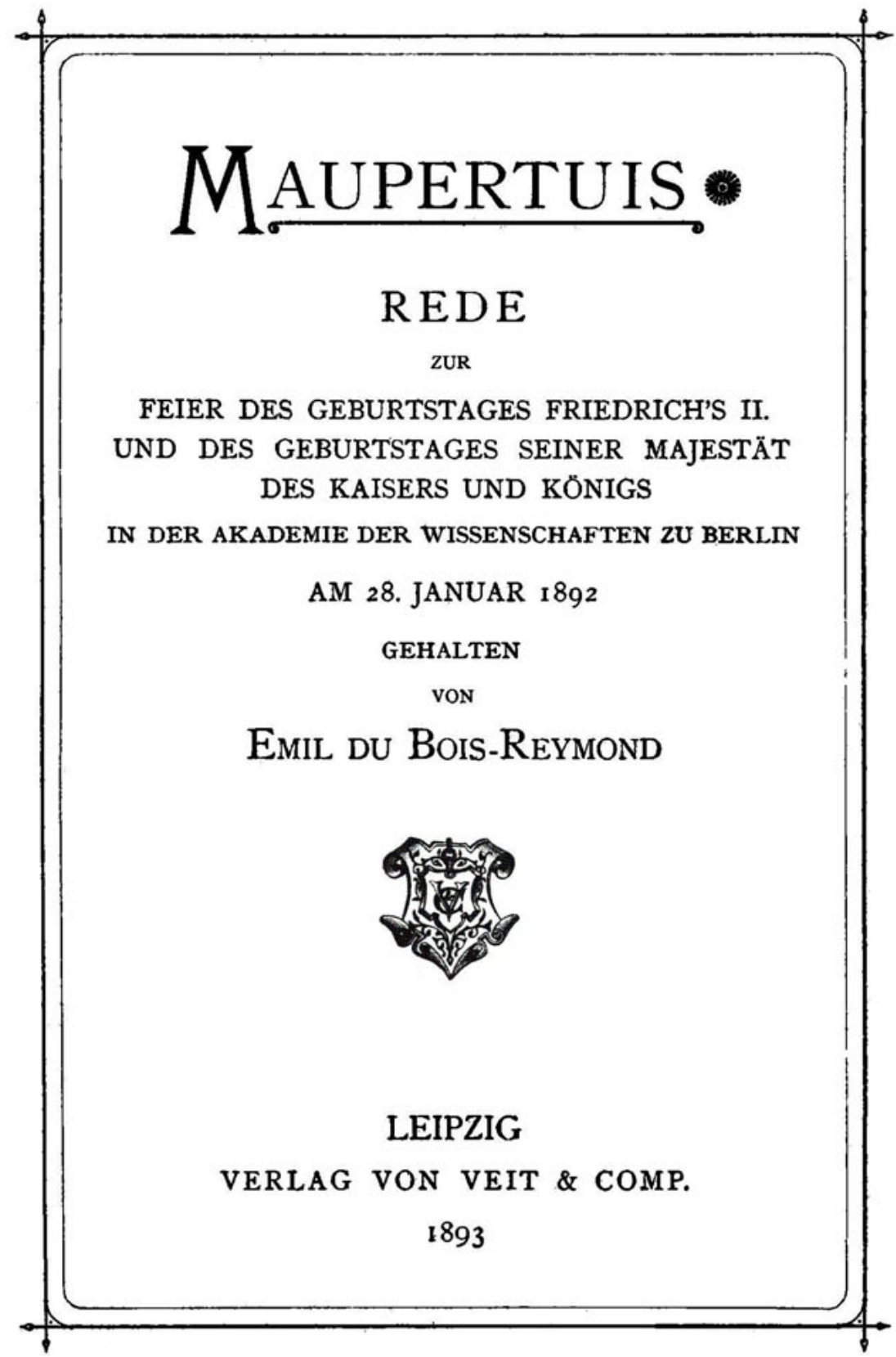


Verlag von Veit \& Comp. in Leipzig.

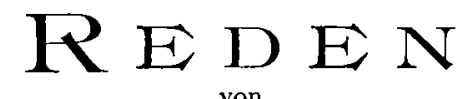

Emil du Bois-Reymond.

Erste und zweite Folge.

2 Bände (erste und zweite Folge). geh. I $7 \mathscr{A}$, eleg. geb. 2 I $\mathcal{A}$.

\section{Erste Folge.}

Litteratur, Philosophie, Zeitgeschichte.

gr. 8. I 886. geh. 8 $\mathfrak{6}$; eleg. geb. Io $\mathfrak{A 6}$.

Inhalt: Voltaire als Naturforscher. - Leibnizische Gedanken in der neueren Naturwissenschaft. - Aus den Tagen des norddeutschen Bundes. - Der deutsche Krieg. - Das Kaiserreich und der Friecle. Ueber die Grenzen des Naturerkennens. - Ueber eine kaiserliche Akademie der deutschen Sprache. - La Mettrie. - Darwin versus Galiani. Culturgeschichte und Naturwissenschaft. - Ueber das Nationalgefühl. Friedrich II. und Rousseau. - Die sicben Welträthsel. - Goethe und kein Ende. - Friedrich II. in englischen Urtheilen. - Die Humboldtdenkmäler vor der Berliner Uuiversität. - Zu Diderot's Gedächtniss.

\section{Zweite Folge.}

Biographie, Wissenschaft, Ansprachen.

gr. 8. 1887. geh. $9 \mathscr{A 6}$; eleg. geb. I I $\mathscr{A}$.

Inhalt: Ueber die Lebenskraft. - Ueber thierische Bewegung. Gedächtnissrede auf Iaul Erman. - Eduard Hallmann's Leben. - Ucber lebend nach Berlin gebrachte Zitterwelse aus Westafrika. - Gedächtnissrede auf Johannes MItiller. - Ueber Universitïtseinrichtungen. - Ueber Geschichte der Wissenschaft. - Der physiologische Unterricht sonst und jetzt. - 'Aus den Llanos'. - Ueber die Uebung. - Ueber die wissenschaftlichen Zustände der Gegenwart. - Die Britische Naturforscherversammlung zu Southampton im Jahre i882. - Darwin und Kopernicus. - Die Berliner Französische Colonie in der Akademie der Wissenschaften. - Akademische Ansprachen.

\section{E. du Bois-Reymond, Adalbert von Chamisso als Naturforscher. I889. 8. geh. $M$ I. 20. Friedrich II. in der bildenden Kunst. I 887. 8. geh. $\quad \mathscr{M}_{1}$. 20 . Naturwissenschaft und bildende Kunst. 8 . 1891. geh.

